\title{
Influência do fíler mineral no comportamento reológico de mástiques asfálticos
}

\author{
Vivian Silveira dos Santos Bardini ${ }^{1}$, Luis Miguel Gutiérrez Klinsky², \\ José Leomar Fernandes Júnior ${ }^{3}$ e Reynaldo Roque ${ }^{4}$
}

\begin{abstract}
Resumo: Este trabalho avalia a influência do fíler mineral e do tipo de ligante no comportamento reológico de mástiques asfálticos ao longo de toda a faixa de temperaturas a que um pavimento pode estar sujeito durante a vida em serviço. Os mástiques asfálticos foram submetidos a ensaios no reômetro de cisalhamento dinâmico (DSR), para determinação do módulo complexo ( $\mathrm{G}^{*}$ ) e do ângulo de fase $(\delta)$, e de fluência de viga à flexão (BBR), para a caracterização de propriedades a baixa temperatura através da rigidez - $\mathrm{S}(\mathrm{t})$ e do módulo de relaxação - $\mathrm{m}(\mathrm{t})$. Os fatores que mais influenciam o $\mathrm{G}^{*}$ e o $\delta$ são o tipo de ligante e a frequência de carregamento, com o tipo e teor de fíler influenciando a elasticidade, e a rigidez dos mástiques apenas quando é considerada a cal hidratada. Os resultados do BBR são significativamente afetados pelo teor de fíler e pelo tipo de ligante. DOI:10.4237/transportes.v20i4.603.
\end{abstract}

Palavras-chave: fíler mineral, mástique asfáltico, propriedades reológicas, Superpave.

\begin{abstract}
This research evaluates the mineral filler content and type influence, and the binder type, on the rheological behavior throughout the temperature range in which the pavement is subject in the service life. Tests were conducted under oscillatory shear, the dynamic shear rheometer (DSR) to characterize the complex modulus $\left(\mathrm{G}^{*}\right)$ and the phase angle $(\delta)$; and in the bending beam rheometer (BBR) to characterize the low temperature properties of the mastics through the flexural creep stiffness $(\mathrm{S}(\mathrm{t}))$ and the $\mathrm{m}$-value. The factors that influence $\mathrm{G}^{*}$ and $\delta$ are the loading frequency and the type of binder, and the filler type and amount only influence the mastic elasticity, and the stiffness only when evaluate the hydrated lime results. The BBR results are significantly affected by the filler amount and type of binder.
\end{abstract}

Keywords: mineral filler, asphaltic mastic, rheological properties, Superpave.

\section{INTRODUÇÃO}

Fíler mineral, ou material de enchimento, é definido como um material constituído de partículas minerais, passando pelo menos $65 \%$ na peneira de $0,075 \mathrm{~mm}$ de abertura de malha quadrada, provenientes não apenas dos próprios agregados empregados na mistura asfáltica, mas também de outras fontes, como pó calcário, cal hidratada, cimento Portland etc.

As partículas maiores do fíler fazem parte do agregado mineral, com a função de preencher os vazios e interstícios dos agregados graúdos, promovendo o contato pontual entre as partículas maiores e dando maior resistência às misturas. Já as partículas menores do fíler se misturam com o ligante asfáltico, aumentando sua consistência e cimentando as partículas maiores, formando o mástique (Craus et al., 1978).

As características do mástique influenciam o comportamento reológico, mecânico, térmico e de sensibilidade à água das misturas asfálticas. A rigidez do mástique também influencia as tensões desenvolvidas e a resistência à fadiga a temperaturas intermediárias, bem como afeta a resistência

\footnotetext{
${ }^{1}$ Vivian Silveira dos Santos Bardini, Departamento de Engenharia de Transportes, Escola de Engenharia de São Carlos, Universidade de São Paulo, São Carlos, SP, Brasil. (e-mail: vibardini@yahoo.com.br).

${ }^{2}$ Luis Miguel Gutiérrez Klinsky, Departamento de Engenharia de Transportes, Escola de Engenharia de São Carlos, Universidade de São Paulo São Carlos, SP, Brasil. (e-mail: chiligk@hotmail.com).

${ }^{3}$ José Leomar Fernandes Júnior, Departamento de Engenharia de Transportes, Escola de Engenharia de São Carlos, Universidade de São Paulo São Carlos, SP, Brasil. (e-mail: leomar@sc.usp.br).

${ }^{4}$ Reynaldo Roque, Universidade da Flórida, Gainesville, EUA. (e-mail: rroque@ce.ufl.edu)
}

Manuscrito recebido em 15/8/2012 e aprovado para publicação em 24/9/2012. Este artigo é parte de TRANSPORTES v. 20, n. 4, 2012. ISSN: 2237-1346 (online). DOI:10.4237/transportes.v20i4.603. à deformação permanente da mistura asfáltica a altas temperaturas e as tensões desenvolvidas e a resistência ao trincamento a baixas temperaturas (Kim et al., 2003).

As propriedades do mástique são determinadas pelo tipo e teor dos seus componentes, pelas propriedades reológicas do ligante asfáltico e pela forma e estrutura dos grãos de fíler. O mástique tem grande influência na estrutura da mistura asfáltica em nível micro estrutural (Tunnicliff, 1962), afetando sua trabalhabilidade, rigidez e propriedades mecânicas finais.

Segundo Bechara et al. (2008), a relação f/a do fíler mineral é a principal variável associada ao efeito do mástique sobre as propriedades mecânicas, determinada pela quantidade de finos na composição granulométrica da mistura asfáltica, em relação ao teor de ligante asfáltico efetivo.

Os fileres, quando combinados com o ligante asfáltico, provocam alterações nas propriedades físicas e químicas dos ligantes, causadas pelas diferentes propriedades dos fileres, em função do tipo, natureza e concentração do fíler na mistura (Kavussi et al., 1997). No mástique, o ligante asfáltico manifesta sua natureza elástica, viscoelástica ou viscosa em função da temperatura ou do tempo de carregamento, enquanto o agregado mineral preserva sua natureza elástica independentemente das condições de temperatura e de carregamento (Faxina et al., 2009).

A adição de fíler provoca modificações no comportamento reológico do mástique asfáltico, com o aumento do módulo complexo e redução do ângulo de fase. Os efeitos são mais significativos e favoráveis em temperaturas altas, aumentando a rigidez do ligante, que tem módulo complexo menor nessa faixa de temperatura. Porém, a baixas temperaturas, o fíler aumenta ainda mais a rigidez do ligante asfáltico, com redução da capacidade de relaxar tensões. A adição de fíler mineral ao ligante asfáltico provoca um au- 
mento do parâmetro $G^{*} / \operatorname{sen} \delta$ da Especificação Superpave, o que é favorável por aumentar a resistência do ligante à deformação permanente; porém, também provoca um aumento do parâmetro $G^{*}$ sen $\delta$, sendo desfavorável em relação ao dano por fadiga sob deformação controlada (Bahia, 1995).

Bahia (1995) constatou que os efeitos do fíler adicionados ao ligante asfáltico são desfavoráveis para suas propriedades em temperaturas baixas e intermediárias, pois o fíler mineral é constituído de partículas muito mais rígidas que as do ligante, proporcionando assim mástiques mais rígidos, sendo que em baixas temperaturas ligantes asfálticos de baixa consistência são mais indicados.

A caracterização das propriedades reológicas do ligante asfáltico deve ser realizada ao longo de toda a faixa de temperaturas e/ ou de tempos de carregamento a que o pavimento pode ser submetido ao longo da sua vida em serviço. Em altas temperaturas o ligante asfáltico atua como lubrificante, permitindo a mistura com o agregado, e quando é resfriado atua como aglutinante para unir os agregados. Nas altas temperaturas o ligante asfáltico se comporta como um líquido viscoso, a baixas temperaturas se comporta como sólido elástico, e em temperaturas intermediárias exibe características tanto de um líquido viscoso quanto de um sólido elástico (Yildrin et al., 2000).

Atualmente, os estudos reológicos em mástiques são realizados em amostras semelhantes àquelas usadas em estudos de ligantes asfálticos puros ou modificados ou na forma de corpos de prova cilíndricos em miniatura, que podem ser moldados ou extraídos de corpos de prova maiores (Castelo Branco, 2008).

A relação fíler/asfalto da Especificação Superpave não é suficiente para avaliar as interações e toda a influência do fíler nas propriedades da mistura asfáltica final. Porém, ensaios que têm como princípio a avaliação das propriedades fundamentais dos materiais, como a determinação de parâmetros reológicos dos materiais asfálticos através dos ensaios da Especificação Superpave, permitem a simulação das solicitações do tráfego e do intemperismo que os ligantes e mástique asfálticos são submetidos em campo (Anderson et al., 1994).

\section{MATERIAIS E MÉTODOS}

O estudo da influência do fíler no mástique asfáltico foi realizado através da caracterização de suas propriedades reológicas. Para isso, foram realizados ensaios de cisalhamento em regime oscilatório (DSR) e ensaios de fluência de viga a flexão, no reômetro de flexão em viga (BBR). A caracterização da rigidez foi realizada através do módulo complexo $\left(G^{*}\right)$ e ângulo de fase $(\delta)$, ao longo de toda a faixa de temperaturas na qual o pavimento pode estar sujeito ao longo da vida de serviço; e as propriedades a baixa temperatura forma caracterizadas através da rigidez à fluência na flexão - $\mathrm{S}(\mathrm{t})$ - e do módulo de relaxamento - $\mathrm{m}(\mathrm{t})$.

A identificação dos fatores e de suas interações que influenciam nas respostas dos ensaios foi realizada através da análise de variância (ANOVA). A ANOVA é uma técnica estatística para comparação simultânea de várias médias, proveniente de amostras distintas, permitindo a verificação da hipótese nula, em que o efeito considerado é significativo. Isso é realizado através da comparação da estimativa do efeito de um tratamento com a estimativa do erro aleatório, podendo-se estabelecer se o efeito do tratamento é ou não significativo (Montgomery e Runger, 2011).

\subsection{Materiais utilizados}

Para a produção dos mástiques, foram utilizados dois tipos de ligante asfáltico, um Cimento Asfáltico de Petróleo (CAP) 50/70 e um CAP 85/100, ambos fornecidos pela empresa Betunel, da cidade de Ribeirão Preto, SP. Foram avaliados quatro diferentes fileres: cal hidratada, cimento Portland, sílica e pó de calcário. Os resultados da determinação da massa especifica real dos fileres (DNER-ME 085/94) estão apresentados na Tabela 1, que também apresenta os valores médios de superfície específica para diferentes fileres, segundo Pinnila (1965). Foi considerado fíler o material $100 \%$ passante na peneira de $0,075 \mathrm{~mm}$ de abertura $\left(n^{\circ} 200\right)$.

Tabela 1. Valores de Massa Específica e Superfície Específica (Se) dos Fileres

\begin{tabular}{lll}
\hline Material & $\begin{array}{l}\text { Massa Específica } \\
\left(\mathbf{g} / \mathbf{c m}^{\mathbf{3}}\right)\end{array}$ & $\begin{array}{l}\boldsymbol{S}_{\boldsymbol{e}} \\
\left(\mathbf{c m}^{2} / \mathbf{g}\right)\end{array}$ \\
\hline Calcário & 2,749 & $2800-3500$ \\
Cal Cálcica & 2,350 & $5000-15000$ \\
Cimento Portland & 3,030 & $2200-2750$ \\
Sílica & 2,635 & $2500-3500$ \\
\hline
\end{tabular}

\subsection{Métodos}

A preparação dos mástiques (fíler mineral e ligante asfáltico) obedeceu ao seguinte procedimento:

i. Determinação da massa específica do ligante asfáltico e do fíler mineral;

ii. Cálculo da massa de ligante asfáltico necessária para a relação fíler-asfalto (f/a) desejada;

iii. Secagem da amostra de fíler em estufa até a constância de massa $\left(100 \pm 5^{\circ} \mathrm{C}\right)$;

iv. Aquecimento da amostra de ligante asfáltico na temperatura correspondente à temperatura para mistura asfáltica, até sua uniformização. Para o CAP $50 / 70$ essa temperatura é de 150 a $154^{\circ} \mathrm{C}$, e para o CAP 85/100 é de 142 a $147^{\circ} \mathrm{C}$;

v. Aquecimento do fíler na temperatura correspondente à temperatura dos agregados para mistura asfáltica, até sua uniformização. Para os mástique compostos pelo CAP 50/70 essa temperatura é de 165 a $169^{\circ} \mathrm{C}$, e para o CAP $85 / 100$ é de 157 a $162{ }^{\circ} \mathrm{C}$;

vi. Colocação da quantidade de ligante asfáltico calculada no item ii em um recipiente previamente aquecido e, logo em seguida, adicionar a quantidade de fíler já separada;

vii. Mistura dos componentes com uma espátula, até que a mistura fique homogênea e tomando-se o cuidado para que não haja perda de material; e

viii. Utilização imediata do mástique em ensaio ou estocada.

\subsubsection{Ensaio de cisalhamento em regime oscilatório}

$\mathrm{O}$ ensaio de cisalhamento em regime oscilatório (DSR) foi realizado em amostras de mástiques compostos pelos fileres de cimento Portland, sílica e pó de calcário, nas relações f/a de 0,$6 ; 0,9$ e 1,2; já para os mástiques compostos pela cal hidratada foram realizados os ensaios apenas nas relações 
f/a de 0,6 e 0,9, pois a mistura do ligante asfáltico com a cal hidratada na relação f/a de 1,2 foi impraticável, devido à baixa massa especifica do fíler, e consequentemente, o grande volume a ser incorporado nessa relação.

O método para o ensaio de cisalhamento dinâmico é o ASTM D D715-05 ("Standard Test Method for Determining the Rheological Properties of Asphalt Binder Using a Dynamic Shear Rheometer"), e o reômetro empregado neste estudo foi o da marca TA Instruments, modelo AR-2000. $\mathrm{O}$ ensaio é adequado para uso quando o módulo de cisalhamento dinâmico varia entre $100 \mathrm{~Pa}$ e $10 \mathrm{MPa}$, valores que são obtido geralmente entre 4 e $88{ }^{\circ} \mathrm{C}$. Os corpos de prova para o ensaio tem $25 \mathrm{~mm}$ de diâmetro e $1 \mathrm{~mm}$ de espessura ou $8 \mathrm{~mm}$ de diâmetro e $2 \mathrm{~m}$ de espessura para serem utilizados entre placas paralelas.

O procedimento de ensaio foi realizado da seguinte forma:

i. Empregando-se a geometria de $25 \mathrm{~mm}$ e distância entre placas (gap) de $1 \mathrm{~mm}$, foi realizada uma varredura de tensão, nas temperaturas de 52, 64, 76 e $88^{\circ} \mathrm{C}$, em uma faixa de frequência entre 0,1 a 100 $\mathrm{rad} / \mathrm{s}$, para determinar a tensão que o material é solicitado, de acordo com a temperatura e a rigidez do material; e

ii. Empregando-se a geometria de $8 \mathrm{~mm}$ e distância entre placas de $2 \mathrm{~mm}$, foi realizada uma varredura de tensão nas temperaturas de $40,28,16$ e $4^{\circ} \mathrm{C}$, em uma faixa de frequência entre 0,1 a $100 \mathrm{rad} / \mathrm{s}$, para determinar a tensão que o material é solicitado, de acordo com a temperatura e a rigidez do material.

A curva mestre foi utilizada para representar o comportamento reológico do material em função da frequência (ou tempo) de carregamento, utilizando as funções reológicas ângulo de fase $(\delta)$ e módulo complexo $\left(\mathrm{G}^{*}\right)$, descrevendo o comportamento do material para a temperatura de referência. Portanto, a curva mestre foi utilizada para caracterizar o ligante e mástique asfáltico não apenas em condições pontuais e sim ao longo de toda a faixa de frequência, ou de tempos de carregamento, a que o pavimento pode estar sujeito durante a vida em serviço.

\subsubsection{Ensaio de fluência de viga à flexão}

Os mástiques asfálticos submetidos ao ensaio de fluência de viga à flexão foram compostos pelos fileres de cimento Portland e pó calcário, nas relações f/a de 0,6 e 1,2; e para os compostos pelo fíler de cal hidratada, nas relações f/a de 0,3 e 0,6 .

O método para o ensaio de fluência de viga à flexão é o ASTM D6648-01 ("Standard Test Method for Determining the Flexural Creep Stiffenes of Asphalt Binder Using the Bending Beam Rheometer - BBR"), e o reômetro empregado neste estudo foi o da Cannon Instrument Company, modelo TEBBR_9728-V30. A norma contém o procedimento utilizado para determinar a rigidez à flexão em fluência (S) e o logaritmo do módulo de relaxação $(\mathrm{m})$, através da medição da deflexão no meio do vão de uma viga prismática simplesmente apoiada com carregamento estático (980 \pm 50 $\mathrm{mN}$ ) aplicada também no meio do vão por 240 segundos, submetido a baixas temperaturas. $\mathrm{O}$ ensaio é realizado em materiais que apresentam valores de rigidez a flexão entre $20 \mathrm{MPa}$ a $1 \mathrm{GPa}$, e pode ser realizado em materiais com ou sem envelhecimento.
Para a realização do ensaio, é realizada a verificação da carga de contato $(35 \pm 10 \mathrm{mN})$ e da carga de ensaio $(980 \pm$ $50 \mathrm{mN}$ ), em seguida o corpo de prova é posicionado e inicia-se o ensaio; o equipamento aplica o pré-carregamento, de $980 \pm 50 \mathrm{mN}$, por $1 \pm 0,1 \mathrm{~s}$ e imediatamente em seguida reduz a carga para $35 \pm 10 \mathrm{mN}$ por $20 \pm 0,1 \mathrm{~s}$; em seguida é aplicada a carga de ensaio por $240 \mathrm{~s}$. São determinadas a carga e a deflexão em função do tempo de carregamento, em intervalos de 0,5 segundos. Com os dados, pode-se determinar a rigidez do corpo de prova nos tempos de carregamento de 8,$0 ; 15,0 ; 30,0 ; 60,0 ; 120,0$ e 240 segundos.

A simulação do envelhecimento de ligantes asfálticos, segundo a Especificação Superpave, dá-se, inicialmente, através do RTFOT, que simula o envelhecimento no curto prazo, e, posteriormente, do PAV, que simula o envelhecimento no longo prazo. Porém, para Anderson et al. (1992), Gluber et al. (1999) e Cooley et al. (1998) o ensaio convencional de envelhecimento a curto prazo (RTFOT) não pode ser utilizado em mástiques porque os fileres se separam do ligante asfáltico em temperaturas altas, como a utilizada neste procedimento (em torno de $163^{\circ} \mathrm{C}$ ). Não há problema em relação à utilização do $\mathrm{PAV}$, que utiliza temperaturas em torno de $100^{\circ} \mathrm{C}$, por não acarretar a redução de viscosidade do ligante asfáltico a ponto de ocorrer a sedimentação do fíler.

O ensaio de fluência de viga a flexão foi realizado em amostras de mástique asfálticos submetidos a simulação de envelhecimento a longo prazo, em que as amostras são submetidas na estufa de vaso pressurizado (PAV) por 20 horas a $100^{\circ} \mathrm{C}$ sob uma pressão de $2,10 \mathrm{MPa}$. Nesse procedimento, $50 \pm 0,5 \mathrm{~g}$ de material é colocado nos recipientes (pratos), formando uma película de aproximadamente 3,2 mm; a amostra é colocada no equipamento (vaso) e após a estabilização da temperatura $\left(100 \pm 0,5^{\circ} \mathrm{C}\right)$, a pressão é colocada $(2,10 \pm 0,1 \mathrm{Mpa})$, durante $20 \mathrm{~h} \pm 10 \mathrm{~min}$; no final do tempo de ensaio, a pressão interna do PAV é liberada lentamente (10 minutos) e as amostras são removidas do equipamento e colocadas em estufa a $163{ }^{\circ} \mathrm{C}$ durante $15 \pm 1$ min, em seguida são retiradas dos pratos e colocadas em recipientes apropriados e levadas para a estufa de vácuo a $170 \pm 5^{\circ} \mathrm{C}$ por $30 \pm 1 \mathrm{~min}$ para a retirada de bolhas.

\section{RESULTADOS}

\subsection{Ensaios de cisalhamento em regime oscilatório}

As Figuras 1, 2, 3 e 4 apresentam as curvas mestre de $\mathrm{G}^{*}$ e $\delta$ para os mástiques compostos pelo CAP 50/70 (a) e CAP $85 / 100$ (b), em função da relação fíler/asfalto, para os fileres de cimento Portland, sílica, pó de calcário e cal hidrata$\mathrm{da}$, respectivamente. A temperatura de referência para a construção das curvas mestre é de $40^{\circ} \mathrm{C}$.

Pode-se perceber que no desenvolvimento da curva mestre de $\mathrm{G}^{*}$ com a frequência, observado nas Figuras de 1 a 4, o material apresenta valor de módulo complexo próximo ao do módulo vítreo em temperaturas baixas (frequência alta) e tem sua rigidez reduzida à medida que a temperatura aumenta (frequência diminui).

A forma da curva mestre é de ligantes asfálticos, em que o módulo aumenta linearmente com a frequência de carregamento das frequências mais baixas até intermediárias, e tende assintoticamente para o módulo de $10^{9} \mathrm{~Pa}$ (módulo vítreo), como relatado por Bechara et al. (2008). 


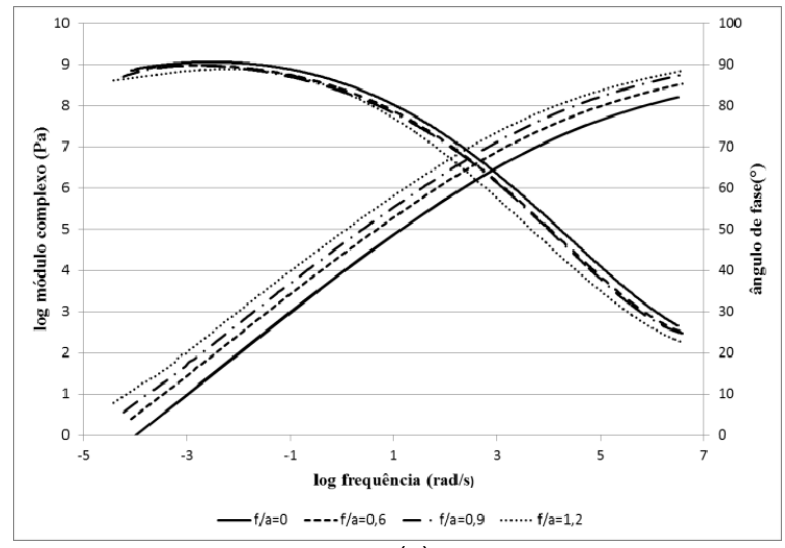

(a)

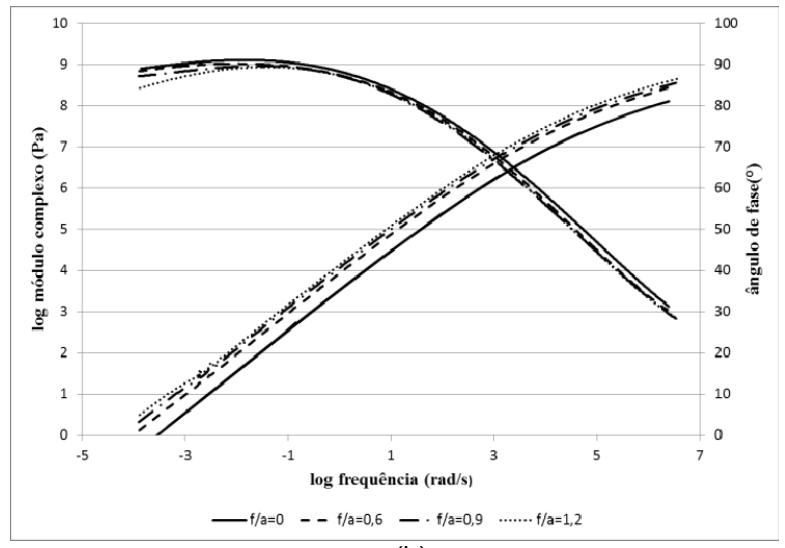

(b)

Figura 1. Curva Mestre de $G^{*}$ em função da frequência, para mástique compostos com o fíler de cimento Portland, em função da relação f/a e (a) CAP $50 / 70$ e (b) $85 / 100$

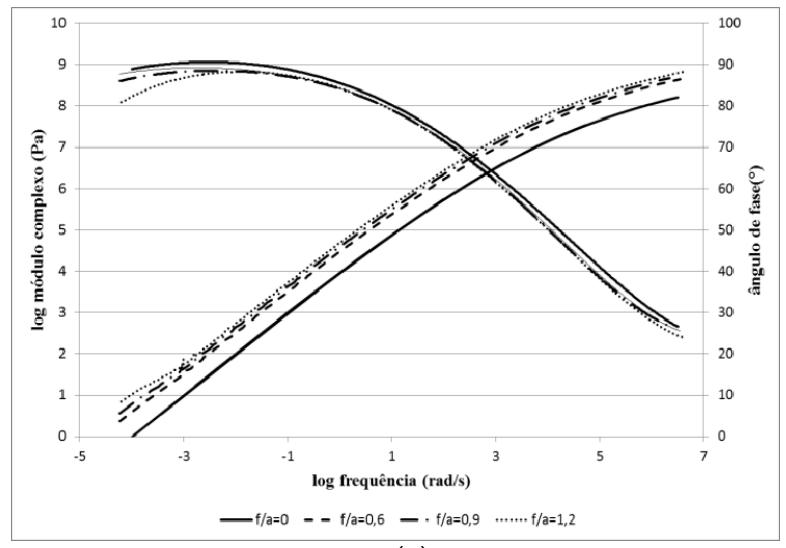

(a)

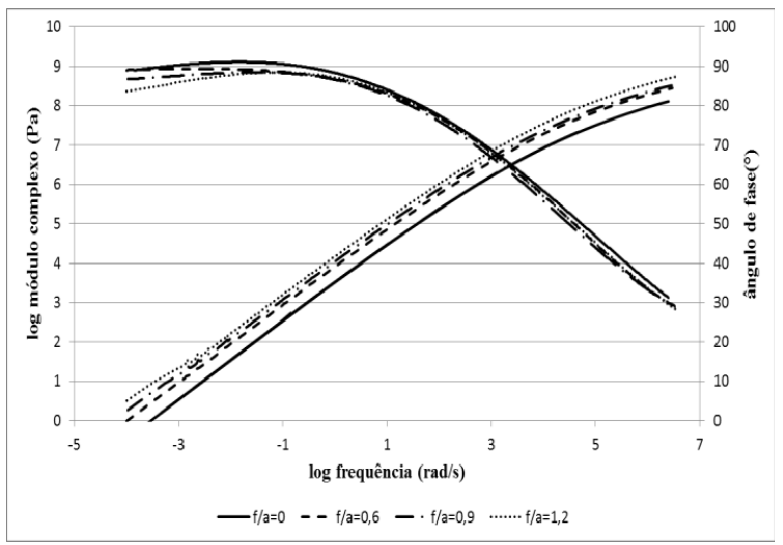

(b)

Figura 2. Curva Mestre de $G^{*}$ em função da frequência, para mástique compostos com o fíler de sílica, em função da relação f/a e (a) CAP $50 / 70$ e (b) $85 / 100$

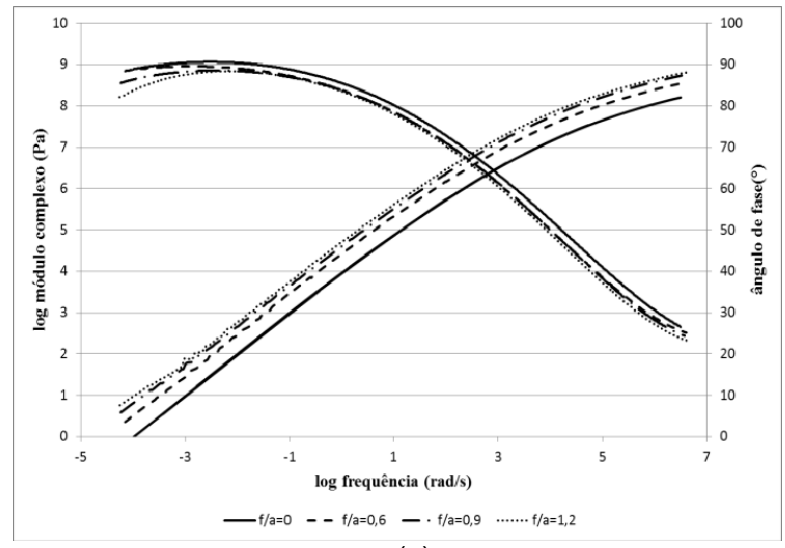

(a)

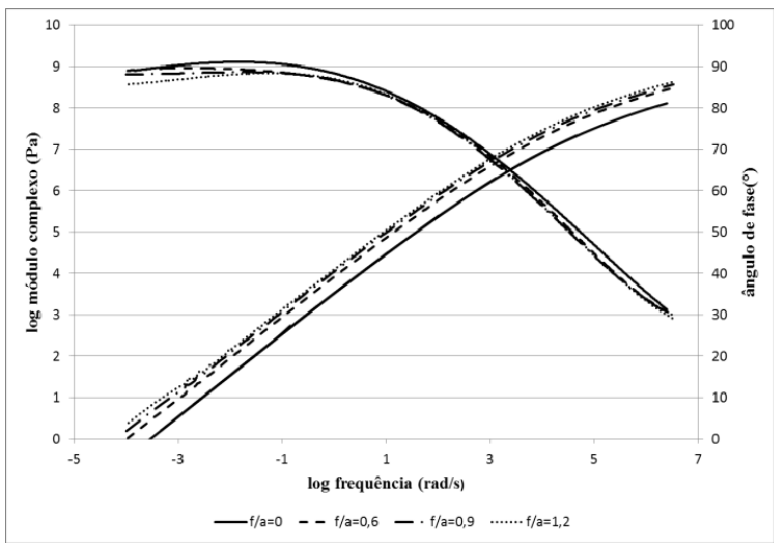

(b)

Figura 3. Curva Mestre de $G^{*}$ em função da frequência, para mástique compostos com o fíler de pó calcário, em função da relação f/a e (a) CAP $50 / 70$ e (b) $85 / 100$

A adição de fíler aumenta os valores de $\mathrm{G}^{*}$ e reduz os valores de $\delta$, tornando o ligante asfáltico mais rígido e mais elástico. $\mathrm{O}$ aumento da rigidez é observado para qualquer frequência de carregamento ou temperatura. A adição de fíler provoca um deslocamento vertical na escala de rigidez, praticamente uniforme ao longo da escala de frequência, e diminui com o aumento da frequência (diminuição da temperatura), indicando que o efeito enrijecedor do fíler é mais significativo em temperaturas altas, que pode se refletir em aumento da resistência a deformação permanente das misturas asfálticas.

Analisando os resultados do ângulo de fase $(\delta)$, a elasticidade aumenta com a adição dos fileres, o que se observa pela redução dos valores de ângulo de fase. O ângulo de fase dos mástiques asfálticos aumenta com a temperatura, uma tendência de variação semelhante a dos ligantes asfálticos. A adição de fíler, em linhas gerais, provoca redução do ângulo de fase, tornando o mástique mais elástico.

O efeito do teor de fíler no mástique (relação f/a) é sutilmente diferente para cada fíler mineral: para os mástiques compostos pela cal hidratada a redução do ângulo de fase é mais notória para frequências mais baixas, para ambos os tipos de ligantes asfálticos; os mástique compostos pelo pó calcário e a sílica também apresentam uma redução do ângulo de fase maior em frequências mais baixas, porém esse comportamento é bem sutil; para os mástique compostos 


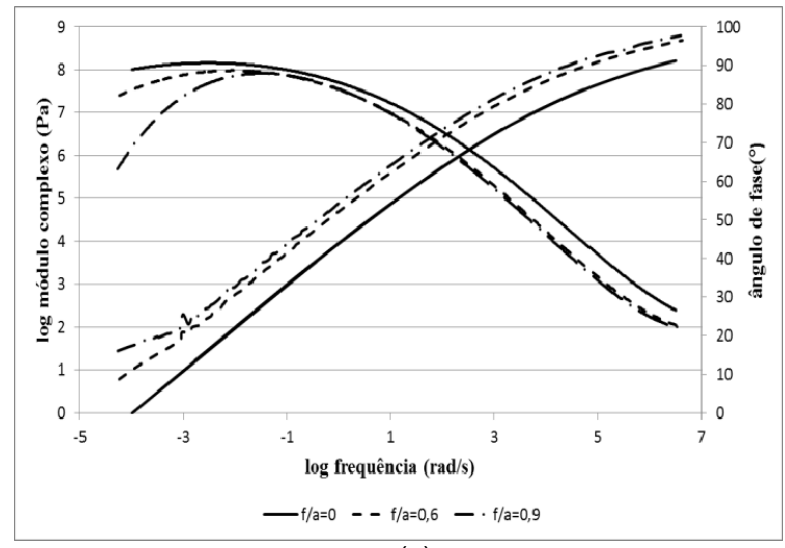

(a)

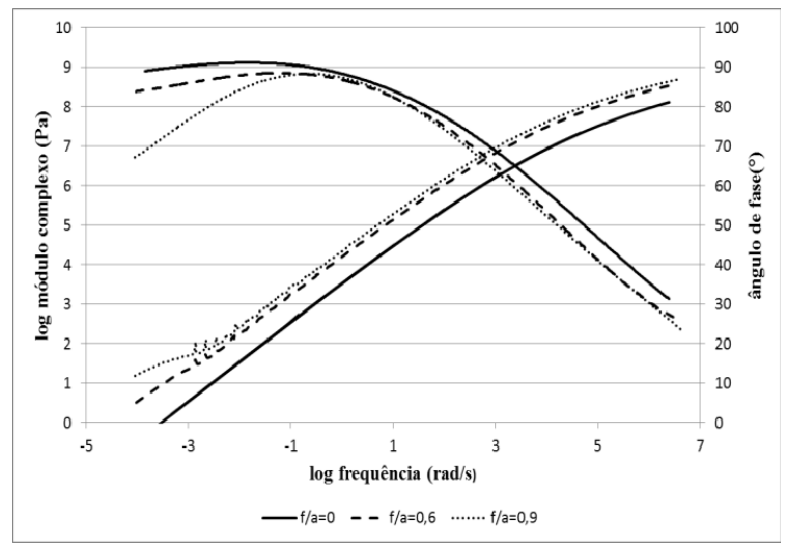

(b)

Figura 4. Curva Mestre de $\mathrm{G}^{*}$ em função da frequência, para mástique compostos com o fíler de cal hidratada, em função da relação f/a e (a) CAP $50 / 70$ e (b) $85 / 100$

Tabela 2. Resumo da ANOVA realizado com os resultados de $\mathrm{G}^{*}$, dos valores de $\mathrm{f}_{0}$ e da influência dos fatores e sua interação, para as análises (1) e (2)

\begin{tabular}{lrllrll}
\hline & \multicolumn{5}{c}{ Análise (1) } & \multicolumn{5}{c}{ Análise (2) } \\
\cline { 2 - 7 } Fator & \multicolumn{1}{c}{$F_{0}$} & $f_{0}$ & influência & \multicolumn{1}{c}{$F_{0}$} & $f_{0}$ & influência \\
\hline A (tipo de fíler) & 24,92 & 3,49 & $\operatorname{sim}$ & 1,04 & 3,89 & não \\
B (teor de fíler) & 226,05 & 3,89 & $\operatorname{sim}$ & 68,94 & 3,49 & $\operatorname{sim}$ \\
C (tipo de ligante ) & 233,43 & 4,75 & $\operatorname{sim}$ & 130,10 & 4,75 & sim \\
D (frequência de carregamento) & 997,97 & 3,89 & $\operatorname{sim}$ & 498,37 & 3,89 & sim \\
AB & 7,97 & 3,00 & $\operatorname{sim}$ & 1,54 & 3,00 & não \\
AC & 2,52 & 3,49 & não & 1,63 & 3,89 & não \\
AD & 31,13 & 3,89 & $\operatorname{sim}$ & 0,42 & 4,75 & não \\
BC & 26,41 & 3,89 & $\operatorname{sim}$ & 11,91 & 3,89 & sim \\
BD & 116,42 & 4,75 & $\operatorname{sim}$ & 40,41 & 3,00 & sim \\
CD & 114,77 & 3,89 & $\operatorname{sim}$ & 71,88 & 3,89 & sim \\
\hline
\end{tabular}

pelo cimento Portland, a redução do ângulo de fase é mais significativa para frequências mais altas, quando combinado com o CAP 50/70, e para frequências mais baixas quando combinado com o CAP 85/100.

Os mástique compostos pelo CAP 50/70 apresentam valores de $\mathrm{G}^{*}$ maiores, quando comparado aos com o CAP $85 / 100$. O fíler de cal hidratada é o fíler que apresenta maior capacidade de enrijecimento, com ambos os ligantes asfálticos; já o cimento Portland apresenta valores de enrijecimento maiores quando combinado ao CAP 50/70, uma vez que, combinado com o CAP 85/100, apresenta enrijecimento similar ao do pó calcário e da sílica, evidenciando que o comportamento do mástique depende da interação físico-química entre o fíler e o ligante asfáltico (Craus et al., 1978). O efeito enrijecedor da cal hidratada pode ser atribuído à forma das partículas e à textura superficial, além de apresentar um grande potencial de atividade físico química com o ligante asfáltico (Kavussi e Hicks, 1997).

Para avaliar a influência dos diferentes fatores - tipo e teor de fíler e tipo de ligante asfáltico - nas propriedades reológicas do mástique foi realizada a análise de variância para os valores de módulo complexo $\left(\mathrm{G}^{*}\right)$ e ângulo de fase

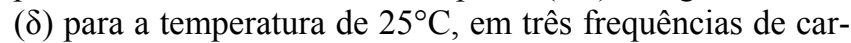
regamento, 0,$1 ; 1,0$ e $10 \mathrm{rad} / \mathrm{s}$, que representam o tráfego lento, médio e rápido, respectivamente.

Para a análise da influência dos diferentes fatores no módulo complexo, primeiramente consideraram-se os fatores tipo de fíler em quatro níveis (sílica, cimento Portland, pó calcário e cal hidratada), teor de fíler em três níveis (f/a $=0,0 ; 0,6$ e 0,9), tipo de ligante asfáltico (CAP 50/70 e
CAP 85/100) e frequência de carregamento $(0,1 ; 1,0$ e 10 $\mathrm{rad} / \mathrm{s})$. A segunda análise foi realizada considerando os fatores tipo de fíler em três níveis (sílica, cimento Portland e pó calcário), teor de fíler em quatro níveis (f/a=0;0,6;0,9 e 1,2), tipo de ligante asfáltico (CAP 50/70 e CAP 85/100) e frequência de carregamento $(0,1 ; 1,0$ e $10 \mathrm{rad} / \mathrm{s})$.

Na Tabela 2 está apresentado o resumo da análise de variância das respostas do módulo complexo, com a resposta da influência dos fatores considerados, para as análises considerando o fator tipo de fíler em 4 e o teor de fíler em 3 níveis (análise (1)) e o tipo de fíler em 3 e o teor de fíler em 4 níveis (análise (2)). O F $\mathrm{F}_{0}$ representa o valor calculado pelo procedimento da ANOVA e $\mathrm{f}_{0}$ é o valor tabelado para o teste $\mathrm{f}$, de acordo com o número de observações e o número de fatores e de suas interações (Montgomery e Runger, 2011); o fator ou as interações entre fatores é considerado influente se $\mathrm{F}_{0}$ é maior que $\mathrm{f}_{0}$.

Os fatores que mais influenciam o módulo complexo são a frequência de carregamento, o tipo de ligante asfáltico e o teor de fíler, como também se pode observar através das curvas mestre. Já o tipo de fíler tem influência apenas quando se considera a cal hidratada, em razão de sua grande atividade.

Para a análise da influência dos diferentes fatores no ângulo de fase, foram realizadas as análises considerando o fator tipo de fíler em 4 e o teor de fíler em 3 níveis (análise (1)) e o tipo de fíler em 3 e o teor de fíler em 4 níveis (análise (2)), como para o módulo complexo. Na Tabela 3 está apresentado o resumo dos valores do teste $\mathrm{f}$ da análise de variância das respostas do ângulo de fase, com a resposta 
Tabela 3. Resumo da ANOVA realizado com os resultados do $\delta$, dos valores de $f_{0}$ e da influência dos fatores e sua interação, para as análises (1) e (2)

\begin{tabular}{lrllrll}
\hline & \multicolumn{5}{c}{ Análise (1) } & \multicolumn{5}{c}{ Análise (2) } \\
\cline { 2 - 7 } Fator & \multicolumn{1}{c}{$F_{0}$} & \multicolumn{1}{c}{$f_{0}$} & influência & \multicolumn{1}{c}{$F_{0}$} & \multicolumn{1}{c}{$f_{0}$} & influência \\
\hline A (tipo de fíler) & 14,70 & 3,49 & $\operatorname{sim}$ & 10,78 & 3,89 & $\operatorname{sim}$ \\
B (teor de fíler) & 60,15 & 3,89 & $\operatorname{sim}$ & 22,68 & 3,49 & $\operatorname{sim}$ \\
C (tipo de ligante) & 666,60 & 4,75 & $\operatorname{sim}$ & 657,89 & 4,75 & $\operatorname{sim}$ \\
D (frequência de carregamento) & 1567,40 & 3,89 & $\operatorname{sim}$ & 1373,24 & 3,89 & $\operatorname{sim}$ \\
AB & 4,05 & 3,00 & $\operatorname{sim}$ & 1,52 & 3,00 & não \\
AC & 2,50 & 3,49 & não & 2,27 & 3,89 & não \\
AD & 9,64 & 3,89 & $\operatorname{sim}$ & 2,81 & 4,75 & não \\
BC & 9,51 & 3,89 & $\operatorname{sim}$ & 5,63 & 3,89 & sim \\
BD & 7,63 & 4,75 & $\operatorname{sim}$ & 3,50 & 3,00 & sim \\
CD & 26,57 & 3,89 & $\operatorname{sim}$ & 26,36 & 3,89 & sim \\
\hline
\end{tabular}

da influência dos fatores considerados, para as análises (1) e (2).

Pode-se perceber, através dos dados da Tabela 3, que os fatores que mais influenciam o ângulo de fase são a frequência de carregamento e o tipo de ligante, o que não é tão expressivo quando se observa as curvas mestre. $\mathrm{O}$ teor de fíler tem influência maior que o tipo de fíler, sendo que os dois fatores influenciam significativamente na resposta do ângulo de fase do mástique.

\subsection{Ensaio de fluência de viga à flexão}

As Figuras 5, 6 e 7 mostram as curvas de rigidez à fluência na flexão $[\mathrm{S}(\mathrm{t})]$ e módulo de relaxação $[\mathrm{m}(\mathrm{t})]$ ao longo do tempo de carregamento para os mástiques compostos pelo fíler de cimento Portland, pó calcário e cal hidratada, respectivamente, em função da relação f/a, para o CAP 50/70

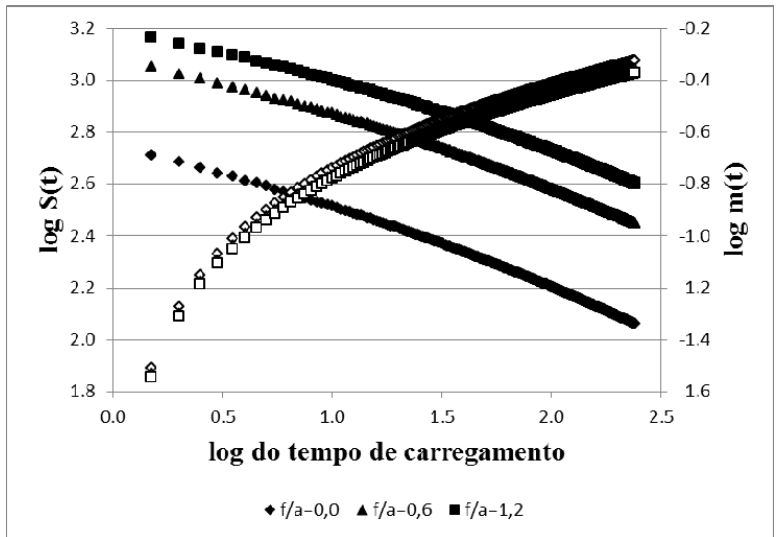

(a) (a) e o CAP 85/100 (b).

A temperatura de ensaio foi determinada nas características do ligante asfáltico, garantindo o atendimento dos valores de limite de rigidez (máximo de $300 \mathrm{MPa}$ ) e de módulo de relaxação (mínimo de 0,3 ), correspondente a um tempo de carregamento de 60 segundos, de acordo com a Especificação Superpave; dessa forma, foi selecionada a temperatura de $-12^{\circ} \mathrm{C}$.

As Figuras 5, 6 e 7 mostram que os mástiques asfálticos apresentam uma tendência de variação da rigidez ao longo do tempo de carregamento semelhante à dos ligantes asfálticos (relação $\mathrm{f} / \mathrm{a}=0,0$ ). A rigidez diminui com o tempo, de forma aproximadamente linear, quando a escala de $\mathrm{S}(\mathrm{t})$ é logarítmica. A utilização do fíler mineral aumenta o valor de $\mathrm{S}(\mathrm{t})$ para todos os tempos de carregamento, que pode ser comparado a um deslocamento vertical da curva do ligante

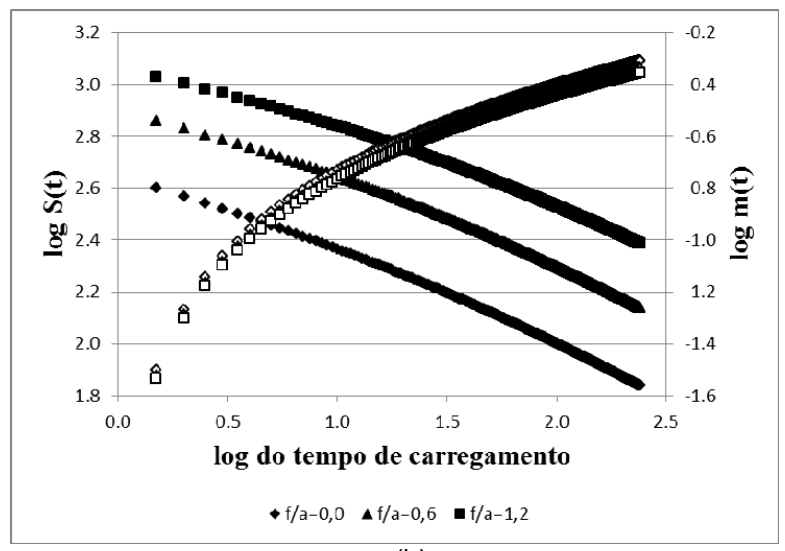

(b)

Figura 5. Curva de $\mathrm{S}(\mathrm{t})$ e $\mathrm{m}(\mathrm{t})$ dos mástiques compostos com o fíler de cimento Portland e (a) CAP 50/70 e (b) CAP 85/100

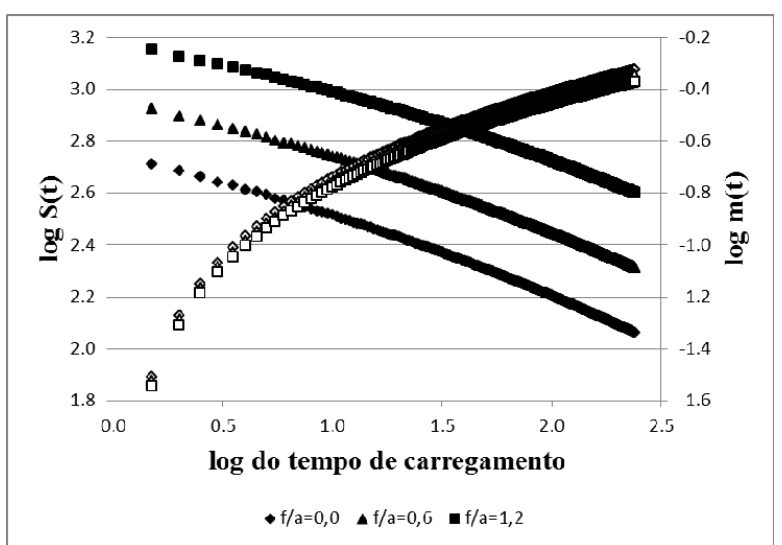

(a)

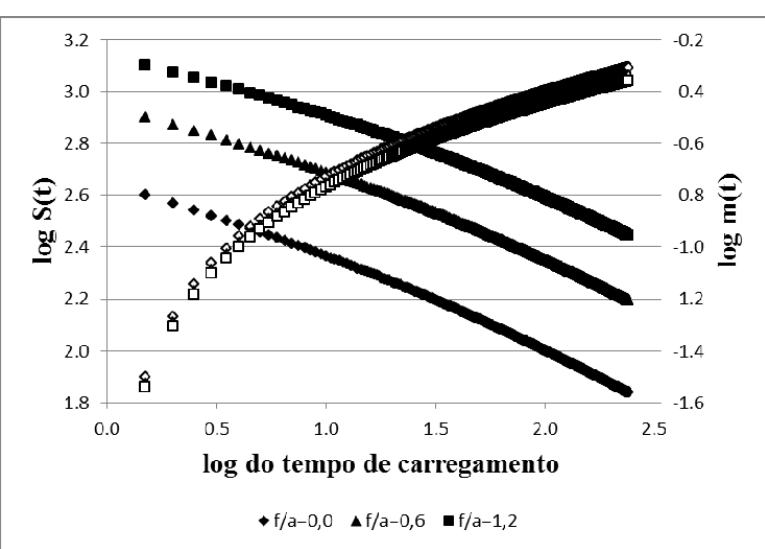

(b)

Figura 6. Curva de $\mathrm{S}(\mathrm{t})$ e $\mathrm{m}(\mathrm{t})$ dos mástiques compostos com o fíler de pó calcário e (a) CAP 50/70 e (b) CAP 85/100 


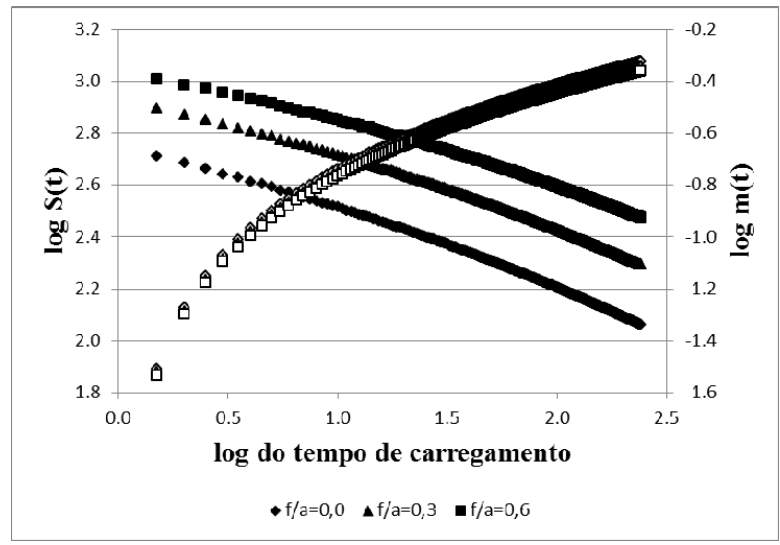

(a)

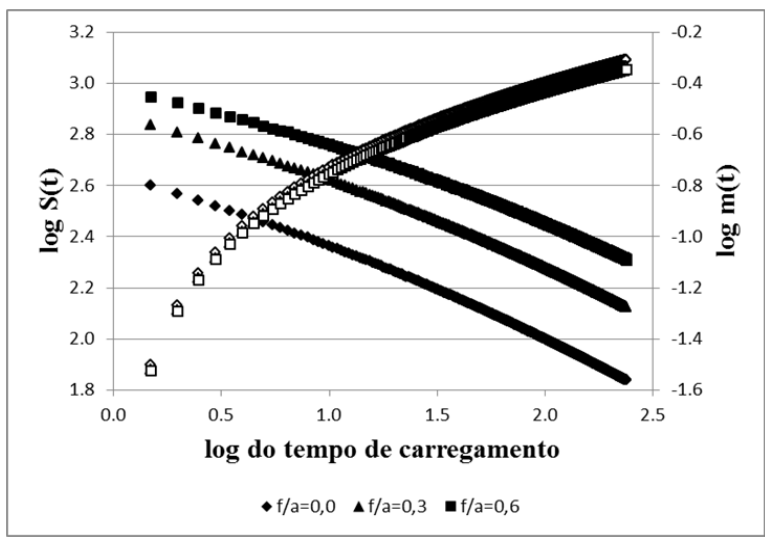

(b)

Figura 7. Curva de $\mathrm{S}(\mathrm{t})$ e $\mathrm{m}(\mathrm{t})$ dos mástiques compostos com o fíler de cal hidratada e (a) CAP 50/70 e (b) CAP 85/100

Tabela 4. ANOVA com resultados de $S(60)$ : valores de $f_{0}$ e influência dos fatores e interações

\begin{tabular}{lrrlrll}
\hline & \multicolumn{5}{c}{ Análise (1) } & \multicolumn{5}{c}{ Análise (2) } \\
\cline { 2 - 8 } Fator & \multicolumn{1}{c}{$F_{0}$} & $f_{0}$ & influência & \multicolumn{1}{c}{$F_{0}$} & $f_{0}$ & influência \\
\hline A (tipo de fíler) & 2,11 & 3,89 & não & 0,72 & 4,75 & não \\
B (teor de fíler) & 184,68 & 4,75 & sim & 1236,94 & 3,89 & sim \\
C (tipo de ligante) & 64,31 & 4,75 & sim & 433,98 & 4,75 & sim \\
AB & 2,11 & 3,89 & não & 11,91 & 3,89 & sim \\
AC & 2,97 & 3,89 & não & 35,34 & 4,75 & sim \\
BC & 9,30 & 4,75 & sim & 32,23 & 3,89 & sim \\
ABC & 2,97 & 3,89 & não & 12,24 & 3,89 & sim \\
\hline
\end{tabular}

Tabela 5. ANOVA com resultados de $\mathrm{m}(60)$ : valores de $\mathrm{f}_{0}$ e influência dos fatores e interações

\begin{tabular}{lrllrll}
\hline & \multicolumn{7}{c}{ Análise (1) } & \multicolumn{7}{c}{ Análise (2) } \\
\cline { 2 - 7 } Fator & \multicolumn{1}{c}{$F_{0}$} & \multicolumn{1}{c}{$f_{0}$} & influência & \multicolumn{1}{c}{$F_{0}$} & \multicolumn{1}{l}{$f_{0}$} & influência \\
\hline A (tipo de fíler) & 0,96 & 3,89 & não & 0,25 & 4,75 & não \\
B (teor de fíler) & 318,09 & 4,75 & sim & 1931,56 & 3,89 & sim \\
C (tipo de ligante) & 105,63 & 4,75 & sim & 594,76 & 4,75 & sim \\
AB & 0,96 & 3,89 & não & 7,34 & 3,89 & sim \\
AC & 2,02 & 3,89 & não & 32,75 & 4,75 & sim \\
BC & 0,17 & 4,75 & não & 6,35 & 3,89 & sim \\
ABC & 2,02 & 3,89 & não & 13,75 & 3,89 & sim \\
\hline
\end{tabular}

asfáltico puro, e esse aumento é maior com maiores teores de fíler.

Dessa maneira, pode-se afirmar que a utilização de maiores teores de fíler pode ser prejudicial quanto ao trincamento a baixas temperaturas. Pode-se observar que há um aumento da rigidez com o aumento do teor de fíler, e que o fíler de cal hidratada apresenta maior rigidez dentre os fileres estudados, para ambos os ligantes asfálticos (CAP 50/70 e CAP 85/100); o cimento Portland, quando combinado com o CAP 50/70, apresenta rigidez similar ao da cal hidratada, porém quando combinado com o CAP 85/100 apresenta rigidez menor que a proporcionada com pó calcário.

Para a análise da influência dos diferentes fatores para os valores de rigidez a fluência na flexão no tempo de carregamento de 60 segundos [S(60)], primeiramente considerou-se o tipo de fíler em três níveis (pó calcário, cimento Portland e cal hidratada), teor de fíler em dois níveis (f/a $=0,0$ e 0,6$)$ e tipo de ligante asfáltico (CAP 50/70 e CAP $85 / 100)$. Na segunda análise, foram considerados o tipo de fíler em dois níveis (pó calcário e cimento Portland), teor de fíler em três níveis (f/a $=0,0 ; 0,6$ e 1,2$)$ e tipo de ligante asfáltico (CAP 50/70 e CAP 85/100).

$\mathrm{Na}$ Tabela 4 está apresentado o resumo dos valores do teste $\mathrm{f}$ da análise de variância das respostas da rigidez a fluência na flexão, com a resposta da influência dos fatores considerados, para as análises considerando o fator tipo de fíler em 3 níveis e o teor de fíler em 2 níveis (análise (1)) e o fator tipo de fíler em 2 níveis e o teor de fíler em 3 níveis (análise (2)). Os fatores que mais influenciam a resposta da rigidez na fluência à flexão são o teor de fíler e o tipo de ligante asfáltico, assim como a interação dos fatores teor de fíler e tipo de ligante.

Para a análise da influência dos diferentes fatores para os valores de módulo de relaxação no tempo de carregamento de 60 segundos $[\mathrm{m}(60)]$, foram considerados o fator tipo de fíler em 3 níveis e o teor de fíler em 2 níveis (análise (1)) e o fator tipo de fíler em 2 níveis e o teor de fíler em 3 níveis (análise (2)), assim como para a rigidez a fluência na flexão. 
$\mathrm{Na}$ Tabela 5 está apresentado o resumo dos valores do teste $\mathrm{f}$ da análise de variância das respostas do módulo de relaxação, com a resposta da influência dos fatores considerados, para as análises (1) e (2). Os fatores que mais influenciam na resposta do módulo de relaxação são o teor de fíler e o tipo de ligante asfáltico, da mesma maneira que para a rigidez a fluência na flexão.

\section{CONCLUSÕES}

Das análises de variâncias das propriedades obtidas no DSR, os fatores que mais influenciam o módulo complexo e o ângulo de fase são a frequência de carregamento e o tipo de ligante asfáltico, como já observado pelas curvas mestre. Para o módulo complexo, o teor de fíler tem influência significativa nas respostas, já o tipo de fíler apresenta influência apenas quando se considera na análise o fíler de cal hidratada, mostrando a grande atividade desse mineral. Já para o ângulo de fase o teor de fíler tem influência maior que o tipo de fíler, sendo que os dois fatores influenciam significativamente na resposta do mástique.

O potencial de enrijecer do fíler aumenta com o aumento da relação f/a, para ambos os tipos de ligante asfáltico, proporcionando mástiques com módulos, em média, de 2 a 5 vezes maiores que os do ligante asfáltico puro, sendo que os aumentos são maiores para a frequência de ensaio correspondente ao tráfego médio $(1,0 \mathrm{rad} / \mathrm{s})$. Porém, o ganho de rigidez não é uma função linear da relação f/a, dependendo também do tipo de ligante asfáltico.

Em relação ao tipo de fíler, a cal hidratada apresentou maior enrijecimento dos mástiques, provavelmente, devido a sua atividade superficial, maior superfície específica e irregularidade superficial. O cimento Portland apresentou grande efeito enrijecedor para os mástiques compostos pelo CAP 50/70, mas não para o CAP 85/100, mostrando que esse fíler apresenta grande atividade superficial, que depende das interações físico-químicas entre a superfície do fíler e do ligante asfáltico Os fileres de pó calcário e sílica apresentaram comportamento similar, em todos os teores estudados, para ambos os ligantes asfálticos, sendo o enrijecimento mais expressivo para o ligante asfáltico mais rígido.

$\mathrm{Na}$ análise de variância das propriedades obtidas no $\mathrm{BBR}$, os fatores que mais influenciam na resposta da rigidez na fluência na flexão e no módulo de relaxação é o teor de fíler e o tipo de ligante asfáltico. Em relação ao tipo de fíler, o fíler de cal hidratada apresenta maior rigidez à fluência na flexão dentre os fileres estudados, para ambos os ligantes asfáltico (CAP 50/70 e CAP 85/100).

O comportamento dos mástiques compostos pelo fíler de cimento Portland depende do tipo de ligante utilizado, pois para o CAP 50/70 ele apresenta valores de rigidez a fluência na flexão próximos ao da cal hidratada, isso comprova que o comportamento de diferentes fileres depende não somente do tipo de fíler ou do tipo de ligantes asfáltico, e sim da interação fíler-ligante asfáltico, da afinidade entre a superfície e composição do fíler e as propriedades do ligante asfáltico.

\section{AGRADECIMENTOS}

À CAPES (Coordenação de Aperfeiçoamento de Pessoal de Nível Superior) pela bolsa de doutorado concedida aos dois primeiros autores deste tra- balho e pela concessão da bolsas do Programa de Doutorado no País com Estágio no Exterior à primeira autora.

\section{REFERÊNCIAS BIBLIOGRÁFICAS}

Anderson, D A., D. W. Christensen, H. U. Bahia, R. Dongré, M. G. Sharma, C. E. Antle e J. Button (1994) Binder Characterization and Evaluation: Volume 3 - Physical Characterization. Washington. Strategic Highway Research Program, National Research Council. Report SHRP-A-369.

Bahia, H. U. (1995) Critical Evaluation of Asphalt Modification Using Strategic Highway Research Program Concepts. Transportation Research Record, n. 1488, p. 82-88.

Bechara, M. F., A. L. Faxina e G. T. P. Fabbri (2008) Avaliação do Comportamento Reológico de Mástiques Asfálticos por meio de Curvas-mestre. Anais do XXII Congresso da Associação Nacional de Pesquisa e Ensino em Transportes, Fortaleza, 2008.

Castelo Branco, V. T. F. (2008) A Unified Method for the Analysis of Nonlinear Viscoelasticity and Fatigue Cracking of Asphalt Mixtures using the Dynamic Mechanical Analyzer. Thesis (PhD), Texas A\&M University, College Station, Texas, EUA.

Craus, J., I. Ishai e A. Sides (1978) Guidelines for use of dust in hot-mix asphalt concrete mixtures. Proceedings of Asphalt Association of Paving Technologists. v. 56, p. 492-516.

Faxina, A. L., G. T. P. Fabbri e J. B. Soares (2009) Efeito do envelhecimento a curto prazo sobre o comportamento reológico de mástiques asfálticos. Anais do XXI Congresso da Associação Nacional de Pesquisa e Ensino em Transportes, Vitória, 2009.

Kavussi, A. e R. G. Hicks (1997) Properties of bituminous mixtures containing different fillers. Proceedings of Asphalt Association of Paving Technologists. v. 66, p. 153-186.

Kim, Y. R., D. N. Little e I. Song, I. (2003) Effect of mineral fillers on fatigue resistance and fundamental material characteristics - mechanic evaluation. Transportation Research Record, n. 1832, p.18. DOI: $10.3141 / 1832-01$.

Montgomery, D. C. e G. C. Runger (2011) Applied Statistics and Probability for Engineers. Fifth Edition. John Wiley \& Sons, Inc.

Pinilla, A. (1965) O sistema filer-betume, algumas considerações sobre sua importância nas misturas densas. Conselho Nacional de Pesquisa. Instituto de Pesquisas Rodoviárias.

Tunnicliff, D. G. (1962) A Review of Mineral Filler. Proceedings of Asphalt Association of Paving Technologists, v. 31, p. 118-150.

Yildirim, Y., M. Solaimanian e T. W. Kennedy (2000) Mixing and Compaction Temperatures for Hot Mix Asphalt. Transportation Research Board. NCHRP - Report 648. 